\title{
Proton Conductivity and Free Volume Properties in Per-Fluorinated Sulfonic acid/PTFE Copolymer for Fuel Cell
}

\author{
H.F.M. Mohamed ${ }^{a, b, *}$, E.E. AbDel-Hady ${ }^{a}$ And M.O. AbDel-Hamed ${ }^{a}$ \\ ${ }^{a}$ Physics Department, Faculty of Science, Minia University, P.O. Box 61519 Minia, Egypt \\ ${ }^{b}$ Renewable Energy Science \& Engineering Department, Faculty of Postgraduate Studies for Advanced Science \\ (PSAS), Beni-Suef University, P.O. Box 62511 Beni-Suef, Egypt
}

\begin{abstract}
The proton conductivity mechanism in per-fluorinated sulfonic acid/PTFE copolymer Fumapem ${ }^{\circledR}$ membranes for polymer electrolyte membranes has been investigated. Three samples of Fumapem ${ }^{\circledR}$ F-950, F-1050 and F14100 membranes with different ion exchange capacity 1.05, 0.95, and $0.71 \mathrm{meq} / \mathrm{g}$, respectively, were used in this study after drying. The $o$-Ps hole volume size $\left(V_{F V, P s}\right)$ was quantified using the positron annihilation lifetime technique while the proton conductivities $(\sigma)$ were measured using LCR Bridge as function of temperature. It was found that as the ion exchange capacity increases, the proton conductivity increases and the free volume expands. Temperature dependences of proton conductivity and the $o$-Ps hole volume size $\left(V_{F V, P s}\right)$ reflect the glass transition temperature of the membrane. A good linear correlation between the reciprocal of the $o$-Ps hole volume size $\left(1 / V_{F V, \mathrm{Ps}}\right)$ and $\log (\sigma)+\Delta E_{a} / 2.303 k_{\mathrm{B}} T$, (where $\Delta E_{a}$ is the activation energy, $T$ is the absolute temperature and $k_{\mathrm{B}}$ is the Boltzmann constant) at different temperatures indicate that the ionic motion in dry Fumapem ${ }^{\circledR}$ is governed by the free volume. A linear relationship between the critical hole size $\gamma V_{i}^{*}$ and the ion exchange capacity was also achieved.
\end{abstract}

DOI: $10.12693 /$ APhysPolA.132.1509

PACS/topics: 78.70.Bj, 82.47.Nj, 72.80.Le, 36.10.Dr, 88.30.J-, 88.30.pf

\section{Introduction}

Over the past several decades, research on alternative energy has increasingly expanded among engineers, researchers and environmentalists. Primary concerns are global warming, the depletion of fossil fuels, and the need to reduce $\mathrm{CO}_{2}$ emissions as the byproduct of the automotive and utility industries. As these concerns have grown to alarming levels, clean energy technologies such as fuel cells have grown exponentially [1]. The most imperative driver of new alternative energy is the conceivable weariness of petroleum products inside the following couple of decades. The key component for the production of alternative energy has been focused on energy efficiency and minimal environmental impact [2]. As a result, fuel cell technology has made a notable and promising debut as one of the most innovative energy options. Among other alternative energy fuel cell types, proton electrolyte membrane fuel cells (PEMFC) have received major attention and were developed for the transportation industry as well as the portable and stationary fuel cell applications [3]. Operated in lower operating temperature conditions (i.e., $60-80^{\circ} \mathrm{C}$ ), PEMFC functions on a very simple principle. PEMFC consists of four main components, which are cathode/anode electrodes, gas diffusion layers, graphite bipolar plate, and proton electrolyte membrane (PEM) [4]. The key element in PEMFC is the polymer

*corresponding author; e-mail: hamdyfm@gmail.com electrolyte membrane, which permits the conduction of just proton ions.

Nafion ${ }^{\circledR}$ is probably the most studied and operated electrolyte for PEM fuel cells [5], but other perfluorocarbon sulfonic acid membranes from Dow, Gore, and Asahi Chemicals are also used and investigated [6]. Membranes usually have a small temperature range in which they are stable. The upper limit of temperature is dictated by the need of humidification of the membrane, as water is a prerequisite for conduction. Improvements in membrane structure and conductivity are made by producing composite membranes. This should be possible in a few routes, one of which comprises of strengthening the perfluorosulfonic membrane by PTFE components, which is the effective approach of Gore and Asahi Chemicals (however, with different procedures). Another possibility is to impregnate a membrane with a solution or with a solid powder to decrease the permeability of the reactant gases. Currently, proton conductive polymer, Fumapem ${ }^{\circledR}$ is a commercially available per-fluorinated sulfonic acid/PTFE copolymer membrane used as the PEM in the PEMFCs.

The correlation between free volume and transport of penetrants through membrane is misused in the preparation of membranes used in a wide variety of processes such as gas separation [7] and electrical energy storage [8]. The term free volume generally refers to disordered voids that occur naturally in polymers or membranes with length scales ranging from 0.1 to $1.5 \mathrm{~nm}[9]$. The proton conductivity must be affected by the electronic state near the ion exchange site, namely hydrophilic site, as well as the structure of free volume. The positron an- 
nihilation lifetime (PAL) technique has been set up as a capable test for microstructures of polymers; specifically, angstrom-sized free volume holes [10]. Positrons brought from a radioactive source into a polymer annihilate either from the free state or positronium (Ps), the positron-electron bound state. Ps can be formed in either a triplet state, ortho-positronium $(o-\mathrm{Ps})$, or a singlet state, para-positronium ( $p$-Ps), depending on the spin orientation of the electron and the positron. A relation between the radius $R$ of a spherical $o$-Ps hole volume size and the observed $o$-Ps lifetimes, $\tau_{3}$, has been proposed by Tao [10] and Eldrup et al. [11] as follows:

$$
\tau_{3}=\left(2-\frac{2 R}{R_{0}}+\frac{1}{\pi} \sin \left(\frac{2 \pi R}{R_{0}}\right)\right)^{-1},
$$

where $R_{0}=R+\Delta R$ and $\Delta R=0.166 \mathrm{~nm}$ is the thickness of the homogeneous electron layer in which the positron in $o$-Ps annihilates [12]. The free volume size $V_{F V, P s}$ in $\mathrm{nm}^{3}$ is calculable as

$$
V_{F V, \mathrm{Ps}}=4 \pi R^{3} / 3 \text {. }
$$

\section{Experimental}

Three samples of perfluorinated sulfonic acid/PTFE copolymers Fumapem ${ }^{\circledR}$ F-14100, Fumapem ${ }^{\circledR}$ F-1050, and Fumapem ${ }^{\circledR}$ F-950 with ion exchange capacity (IEC) $0.71,0.95$, and $1.05 \mathrm{meq} / \mathrm{g}$, respectively, were purchased from FuMA-Tech, St. Ingbert, Germany. The chemical structure of the samples under study is shown in Fig. 1.

$$
\left.\left.-\left(\mathrm{CF}_{2}-\mathrm{CF}_{2}\right)\right)_{\mathrm{O}}\left(\underset{\mathrm{CF}_{3}}{\mathrm{CF}}-\mathrm{CF}_{2}\right)_{\mathrm{y}}\right]_{\mathrm{n}}-\underset{\mathrm{CF}}{\mathrm{C}}-\mathrm{O}-\mathrm{CF}_{2}-\mathrm{CF}_{2}-\mathrm{SO}_{3} \mathrm{H}
$$

Fig. 1. Chemical structure of Fumapem ${ }^{\circledR}$ F-950, Fumapem ${ }^{\circledR}$ F-1050, and Fumapem ${ }^{\circledR}$ F-14100.

The free volume was calculated from the PAL data as discussed in Eqs. (1) and (2). Fast-fast coincidence system with a time resolution of 250 ps was used for the PAL measurements. PAL spectra were recorded at various temperatures up to $140^{\circ} \mathrm{C}$ with 10 degree steps. Before the measurements, the samples were dried by evacuation for one day at room temperature $\left(\approx 25^{\circ} \mathrm{C}\right)$. The source correction was about $9 \%$ and contributed to the short lifetime components. Since we were interested in the long-lived component, this absorption was not separated in the analysis of the lifetime spectra. The PAL spectra, having about one million total counts, were analyzed into three lifetime components using the PALSFit3 program [13] without constraints.

Wide angle X-ray diffraction (WAXD) was measured for the present samples by Ultima IV (Rigaku Corporation) with a $285 \mathrm{~mm}$ goniometer. A parallel monochromatic X-ray beam acquired by reflection of $\mathrm{Cu} K_{\alpha}$ radiation $(\lambda=1.542 \AA)$ from a fine focus $\mathrm{X}$-ray tube working at $40 \mathrm{kV}$ and $40 \mathrm{~mA}$ by a parabolic multi-layer membrane mirror was utilized. Scattering profiles were recorded with a scintillation one-dimension position-sensitive detector over a range of $5^{\circ}<2 \theta<70^{\circ}$ with a step of $0.01^{\circ}$.

At constant temperature, the conductance $G$ for Fumapem ${ }^{\circledR}$ F-950, Fumapem ${ }^{\circledR}$ F-1050, and Fumapem ${ }^{\circledR}$ F-14100 was measured using a Hioki 3532 LCR meter as a function of frequency $(100 \mathrm{~Hz}-1 \mathrm{MHz})$. All the measurements were carried out in vacuum and at temperature range from 30 to $140{ }^{\circ} \mathrm{C}$. The proton conductivity $(\sigma)$ was calculated with accuracy $\pm 2 \%$ as [14]:

$$
\sigma=\frac{G d}{A}
$$

where $G$ is the measured conductance as a function of frequency, $d$ is the thickness of the sample, and $A$ is the cross-sectional area of the electrode.

\section{Results and discussion}

Figure 2 shows the temperature dependence of the free volume $V_{F V \text {,Ps }}$ for dry Fumapem ${ }^{\circledR}$ F-14100, F-1050 and F-950. It is clear from the figure that the free volume of all the samples is considerably enlarged by thermal expansion. Heating scans show an abrupt change of the thermal expansion coefficient of the free volume 75 $115^{\circ} \mathrm{C}$ which may be attributed to $\alpha$-transition caused by the glass transition temperature $\left(T_{g}\right)$ of Fumapem ${ }^{\circledR}$. This transition is associated with the beginning of longrange mobility of both the main- and side-chains, which is encouraged by a significant debilitating of the electrostatic associations within the ionic aggregates. It is intriguing to take note of that Fumapem ${ }^{\circledR}$ F-950 with higher IEC (1.05 meq/g) and minimal bigger free volume than the other samples. Table I illustrates the thermal expansion coefficient of free volume which was calculated using the well known formula [15] as

$$
\alpha=\frac{\Delta V}{V_{0} \Delta T},
$$

where $\Delta V / \Delta T$ represents the slope of the straight line and $V_{0}$ is the initial free volume. It is clear that the thermal expansion coefficient of free volume larger above $T_{g}$ for the three samples suggests that the backbone segmental motions significantly contribute to the free volume at high temperatures.

TABLE I

The thermal expansion coefficient $\alpha\left[{ }^{\circ} \mathrm{C}^{-1}\right]$ of free volume hole for dried Fumapem ${ }^{\circledR}$ samples.

\begin{tabular}{c|c|c}
\hline \hline Sample & \multicolumn{2}{|c}{$\alpha\left[{ }^{\circ} \mathrm{C}^{-1}\right]$} \\
\cline { 2 - 3 } Fumapem ${ }^{\circledR}$ & below $T_{g}$ & above $T_{g}$ \\
\hline F-11400 & $7.1 \times 10^{-3}$ & $1.7 \times 10^{2}$ \\
F-1050 & $8.5 \times 10^{-3}$ & $1.8 \times 10^{2}$ \\
F-950 & $7.7 \times 10^{3}$ & $2.8 \times 10^{2}$
\end{tabular}

The temperature dependence of the o-Ps intensity $I_{3}$ for all the Fumapem ${ }^{\circledR}$ samples changes only slightly with 


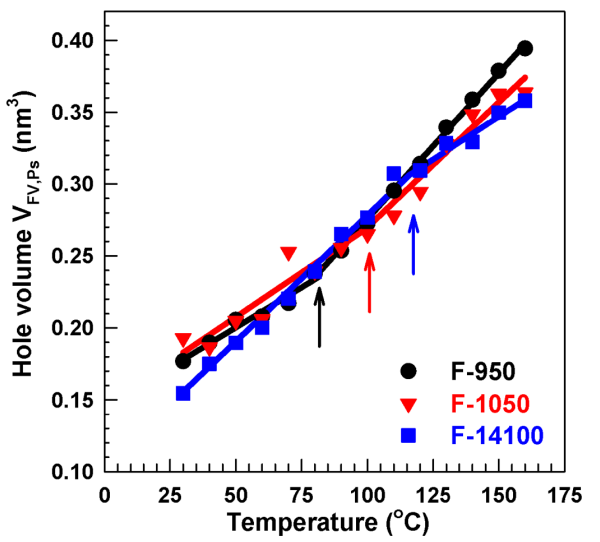

Fig. 2. Free volume hole $V_{F V \text {,Ps }}$ deduced from Eqs. (1) and (2) as a function of temperature for dried Fumapem ${ }^{\circledR}$ samples. The error bars are within the size of the symbol.

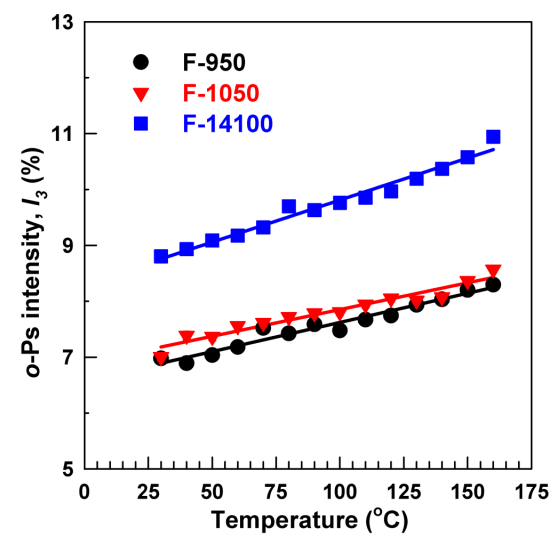

Fig. 3. The temperature dependence of the $o$-Ps intensity $I_{3}$ for dried Fumapem ${ }^{\circledR}$ samples. The error bars are within the size of the symbol.

temperature, indicating that Ps formation does not essentially rely upon temperature as appears in Fig. 3. It is clear that sample with low IEC (Fumapem ${ }^{\circledR}$ F14100) has high $I_{3}$ compared with that in high $I E C$ (Fumapem ${ }^{\circledR}$ F-950 and/or Fumapem ${ }^{\circledR}$ F-1050). A synthetic structure or compound that catches an electronpositron pair, which would otherwise recombine with each other to Ps, can suppress the formation of Ps.

Figure 4 shows the wide angle X-ray diffraction (WAXD) for the as received three Fumapem ${ }^{\circledR}$ samples with different $I E C$ at room temperature $\left(25^{\circ} \mathrm{C}\right)$. A sharp peak around $2 \theta \approx 17.5^{\circ}, 17^{\circ}$, and $16^{\circ}$ for sample with $I E C=0.71,0.95$, and $1.05 \mathrm{meq} / \mathrm{g}$, respectively, is superimposed on an amorphous halo over a range of $2 \theta=10-22^{\circ}$. The peak can be indexed as the (100) reflection of the hexagonal structure of polytetrafluoroethylene (PTFE)-like crystallites in Fumapen ${ }^{\circledR}$ similar to Nafion ${ }^{\circledR}[16]$. If we use the way of Park and Yamazaki [17], the relative crystallinity can be determined where the WAXD pattern is analyzed in the range of $2 \theta$ from 10 to $25^{\circ}$ as shown in Fig. 5 for the different mem-

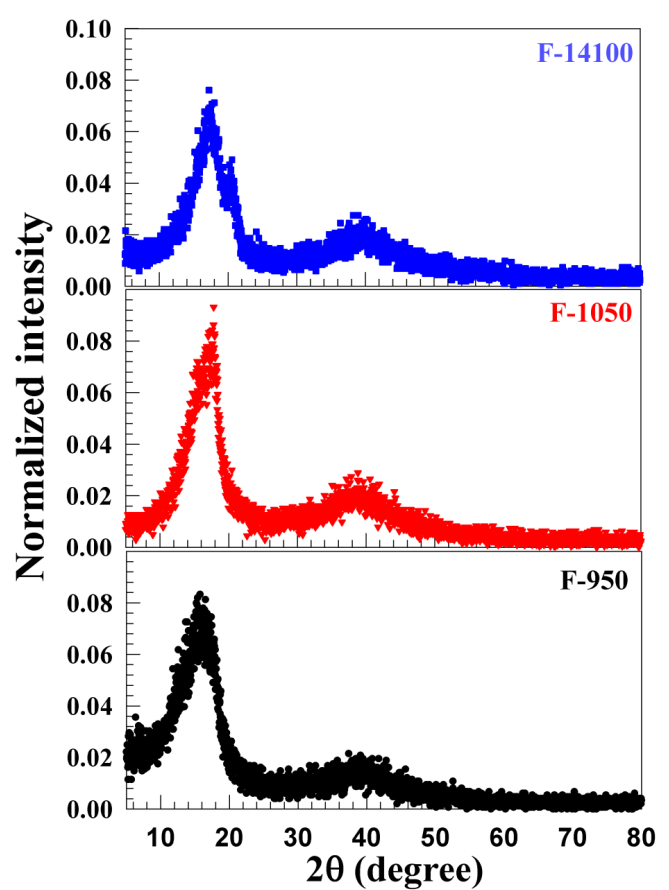

Fig. 4. The wide angle X-ray pattern for Fumapem ${ }^{\circledR}$ samples at room temperature $\left(25^{\circ} \mathrm{C}\right)$.

branes. Measured data are shown by dots which is the convolution of the two peaks profiles. For Fumapem ${ }^{\circledR}$ F-14100, IEC (0.71 meq/g), an amorphous component presented with a peak at $\approx 17.2^{\circ}$ and its full width at half maximum (FWHM) is $2.2^{\circ}$ while a crystalline component presented with a peak at $\approx 20.7^{\circ}$ and its FWHM is $0.5^{\circ}$. For Fumapem ${ }^{\circledR}$ F-1050, IEC $(0.95 \mathrm{meq} / \mathrm{g})$, the peak at $16^{\circ}$ with its FWHM $2.3^{\circ}$ presented the amorphous component while the crystalline component peak is at $17.7^{\circ}$ and its FWHM is $0.6^{\circ}$. Finally, for Fumapem ${ }^{\circledR}$ F-950 with $I E C(1.05 \mathrm{meq} / \mathrm{g})$, the amorphous and crystalline components represented by a peak at $14.7^{\circ}$ and $17.0^{\circ}$ with FWHM value $2.5^{\circ}$ and $1.4^{\circ}$, respectively. The relative crystallinity was calculated from the area under the crystalline and amorphous peaks and is found to be 6.4 , 21.3 and $31.9 \%$ for Fumapem ${ }^{\circledR}$ F-14100, F-1050, and F-950, respectively. The crystalline reflection is weakened in the Fumapen ${ }^{\circledR}$ F-14100 in comparison with the Fumapen ${ }^{\circledR}$ F-950, suggesting that the decrease of $I E C$ makes the regular arrangement of the molecular chains difficult and the crystallinity is decreased. The Bragg spacing $d$ can be calculated as

$$
n \lambda=2 d \sin \theta
$$

where $n$ is order parameter and $\lambda$ is the wavelength. Figure 6 shows the Bragg spacing for the crystalline peak of Fumapem ${ }^{\circledR}$ samples at different $I E C$. The Bragg spacing increased with $I E C$ which reveals that the cluster size become larger with the increase of $I E C$ values.

Regardless of temperature, increasing the $I E C$ inhibits $I_{3}$. Since free volumes favorable for Ps formation are in the amorphous region of a polymer, Ps formation is ex- 


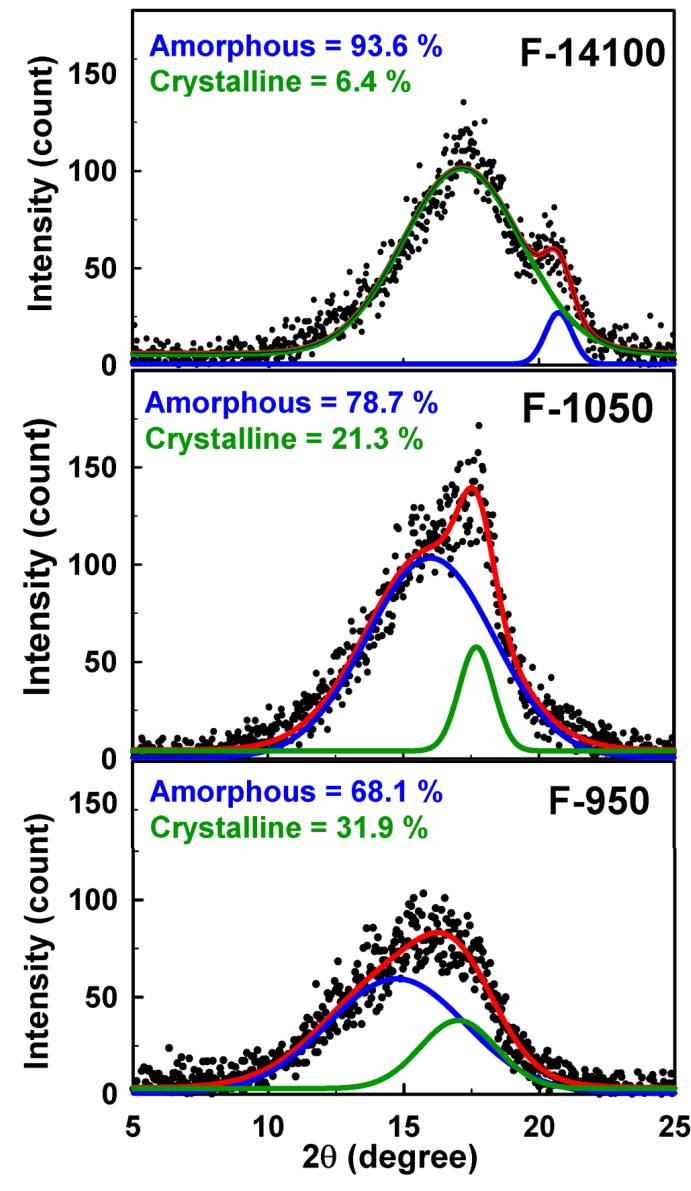

Fig. 5. The wide angle X-ray pattern for Fumapem ${ }^{\circledR}$ samples after deconvolution (red) into crystalline (green) and amorphous (blue) peaks.

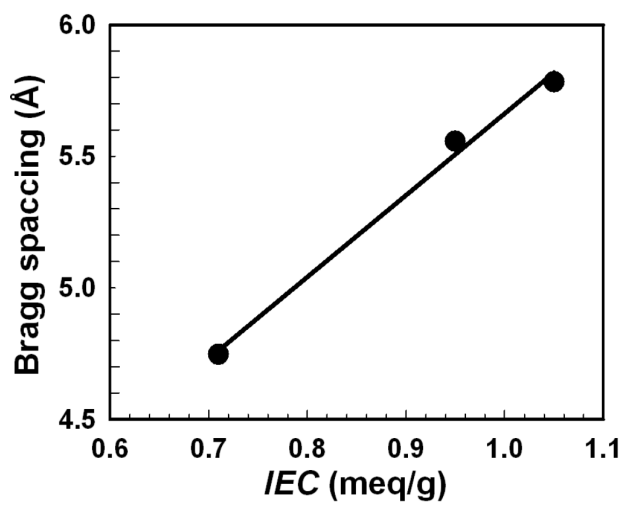

Fig. 6. The relation between Bragg spacing and IEC.

pected to be enhanced with decrease of crystallinity [18]. However, all the Fumapen ${ }^{\circledR}$ samples have the $o$-Ps intensity $I_{3}$ less than half the value of PTFE, in spite of their consistently lower crystallinity [19]. Therefore, the variations of Ps formation upon $I E C$ can be fully accounted for by the degree of crystallinity. Apart from crystallinity, a chemical structure or compound that captures an electron-positron pair, which would otherwise recombine with each other to Ps, can inhibit the formation of Ps [20]. Comparison of the chemical structure between Fumapen ${ }^{\circledR}$ and PTFE (the chemical structure $\mathrm{CF}_{2} \mathrm{CF}_{2}$, i.e. there is no $\mathrm{SO}_{3} \mathrm{H}^{+}$groups) suggests that the reduced $\mathrm{Ps}$ formation in the ionomer may be due to the inhibition effect of the electron-accepting $\mathrm{SO}_{3} \mathrm{H}^{+}$. If this is the case, our results in Figs. 3 and 5 suggest that increase of $I E C$ ( i.e., increase of the concentration of $\mathrm{SO}_{3} \mathrm{H}^{+}$groups) inhibits Ps formation and increase of the degree of crystallinity.

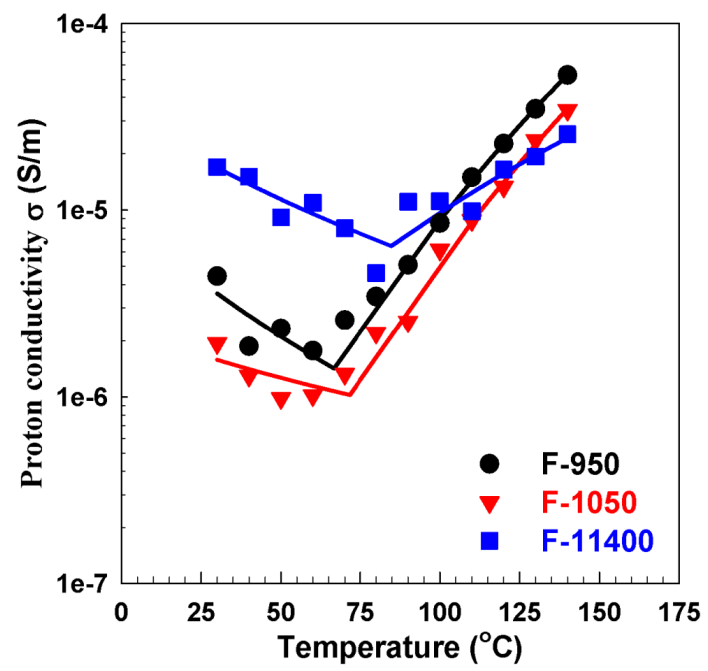

Fig. 7. The temperature dependence of the proton conductivity $\sigma$ for dried Fumapem ${ }^{\circledR}$ samples.

The temperature dependence of the proton conductivity for the three Fumapem ${ }^{\circledR}$ is shown in Fig. 7. In the first zone of the figure (below $T_{g}$ ), the proton conductivity decreases as the temperature increases up to $T_{g}$. This behaviour can be interpreted as follows: when the sample is heated up, it loses its surface and bound water gradually, leading to a decrease in the ionomer cluster order responsible for the proton transport. In the second zone after $T_{g}$ it is clear that the proton conductivity monotonically increases with temperature. It was reported that [21] the variation in proton conductivity with temperature in a polymer electrolyte was assigned to segmental motion, which increases the free volume of the polymer and either allows the ions to hop from one site to another or facilitates the translational ionic motion. By way of increasing the amorphous region, the polymer chain gains faster internal modes in which bond rotations produce segmental motion to inter- and intrachain ion hopping, and accordingly the level of proton conductivity turns out to be high.

The proton conduction mechanism in the membranes is known to occur by two routes. The first route is a proton hopping or jumping mechanism, also known as the Grotthuss model [22], in which a proton is passed through 
a channel of water molecules; the protons are transferred from one vehicle (uncharged molecule) to the other by hydrogen bonds. The second route is a vehicle mechanism, in which a proton combines with molecules, producing a complex which diffuses through the membrane. From the correlation between proton conductivity and temperature, the activation energy $E_{a}$ can be calculated from the use of the Arrhenius equation [23]:

$$
\sigma=\sigma_{0} \mathrm{e}^{-\frac{\Delta E_{a}}{k_{\mathrm{B}} T}}
$$

where $\sigma_{0}$ is the preexponential factor, $\Delta E_{a}$ is the activation energy, $k_{\mathrm{B}}$ is the Boltzmann constant and $T$ is the absolute temperature. The activation energy values are listed in Table II for the three Fumapem ${ }^{\circledR}$ samples before and after $T_{g}$, respectively. It was reported that [24] for the hopping mechanism, the activation energy for proton conductivity should be above $0.15 \mathrm{eV}$, but lower than this value it is in a vehicle mechanism.

TABLE II

The activation energy $\Delta E_{a}$ for dried Fumapem ${ }^{\circledR}$ samples; below $T_{g}$ the reaction is exothermic $\left(\Delta E_{a}<0\right)$ while above $T_{g}$ the reaction is endothermic $\left(\Delta E_{a}>0\right)$.

\begin{tabular}{c|c|c|c}
\hline \hline Sample & IEC & \multicolumn{2}{|c}{$\Delta E_{a}[\mathrm{eV}]$} \\
\cline { 3 - 4 } Fumapem $^{\circledR}$ & {$[\mathrm{meq} / \mathrm{g}]$} & below $T_{g}$ & above $T_{g}$ \\
\hline F-11400 & 0.71 & -0.16 & 0.31 \\
F-1050 & 0.95 & -0.09 & 0.63 \\
F-950 & 1.05 & -0.22 & 0.60
\end{tabular}

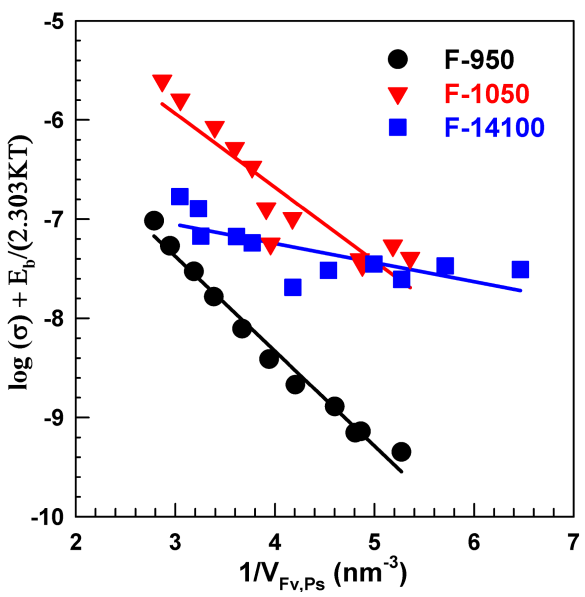

Fig. 8. The correlation between $\log (\sigma)+$ $\Delta E_{a} / 2.303 k_{\mathrm{B}} T$ and reciprocal $o$-Ps hole volume size $\left(1 / V_{F V, \mathrm{Ps}}\right)$ for dried Fumapem ${ }^{\circledR}$ samples.

In order to establish a correlation between the ionic conductivity $\sigma$ and the free volume $V$, the model suggested by Miyamoto and Shibayama [25] has been applied

$$
\sigma=\sigma_{0} \exp \left(-\frac{\gamma V_{i}^{*}}{V}-\frac{\Delta E a}{k_{\mathrm{B}} T}\right),
$$

where $\sigma_{0}$ is the preexponential factor (constant), $\gamma$ is a numerical factor between 0.5 and 1.0 to correct the overlap of free volume and polymer segments [25] and $V_{i}^{*}$ is the critical volume required for transport of an ion. The $o$-Ps hole volume size $\left(V_{F V, P s}\right)$ will be used in state of the

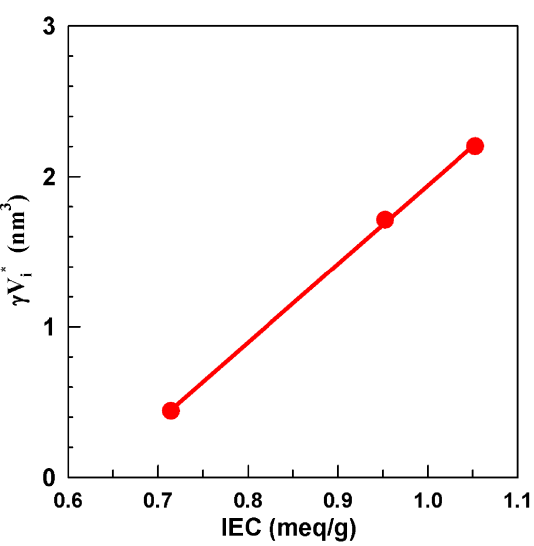

Fig. 9. The correlation between IEC and $\gamma V_{i}^{*}$ for dried Fumapem ${ }^{\circledR}$ samples.

free volume $(V)$ in Eq. (7). Figure 8 shows the correlation between $\log (\sigma)+\Delta E_{a} / 2.303 k_{\mathrm{B}} T$ and the reciprocal of the $o$-Ps hole volume size $\left(1 / V_{F V, \mathrm{Ps}}\right)$ for Fumapem ${ }^{\circledR}$ F-14100, F-1050, and F-950. A linear correlation was obtained indicating that the ionic conductivity is controlling by the free volume in the polymers under study. This behaviour is similar to the data of Pas el al. [26] who found the same behaviour for polymer electrolyte. From the slopes of the straight lines shown in Fig. 8, the critical hole size $\gamma V_{i}^{*}$ was calculated and represented as a function of $I E C$ as shown in Fig. 9. It is clear from the figure that there is a linear correlation between the $I E C$ and the critical hole size $\gamma V_{i}^{*}$.

\section{Conclusions}

In the present work, the proton conductivity and free volume for perfluorinated sulfonic acid/PTFE copolymers (Fumapem ${ }^{\circledR}$ F-14100, Fumapem ${ }^{\circledR}$ F-1050, and Fumapem ${ }^{\circledR}$ F-950) have been studied. The degree of the crystallinity deduced from WAXD increases with increasing $I E C$. The free volume deduced by PAL spectroscopy was enlarged and the proton conductivity was increased (except for F-14100) with increasing $I E C$. Good linear correlations between the reciprocal of the $o$-Ps hole volume size $\left(1 / V_{F V, \text { Ps }}\right)$ and $\log (\sigma)+\Delta E_{a} / 2.303 k_{\mathrm{B}} T$, indicating that proton conductivity in perfluorinated sulfonic acid/PTFE copolymers is governed by the hole volume. The results demonstrated that the PAL is a powerful technique to study the mechanism of proton conductivity in PEMFC.

\section{Acknowledgments}

The authors are grateful to A. Ohira of Fuel Cell Cutting-Edge Center (FC-Cubic), Technology Research Association, Japan for enlightening suggestions. 


\section{References}

[1] G. Hoogers, in: Fuel Cell Technology Handbook, Ch. 9, CRC Press, Boca Raton (FL) 2002.

[2] B. Sørensen, in: Hydrogen and Fuel Cells: Emerging Technologies and Applications, Elsevier Academic Press, London 2005.

[3] R.P. O'Hayre, S.W. Cha, W. Colella, F.B. Prinz, in: Fuel Cell: Fundamentals, Wiley, New York 2005.

[4] F. Barbir, in: PEM Fuel Cells: Theory and Practice, Elsevier Academic Press, MA 2005.

[5] H.F.M. Mohamed, K. Ito, Y. Kobayashi, N. Takimoto, Y. Takeoka, A. Ohira, Polymer 49, 3091 (2008).

[6] M. Wakizoe, O. Velev, A.S. Srinivasan, Electrochim. Acta 40, 335 (2001).

[7] H.B. Park, C.H. Jung, Y.M. Lee, A.J. Hill, S.J. Pas, S.T. Mudie, E.V. Wagner, B.D. Freeman, D.J. Cookson, Science 318, 254 (2007).

[8] O. Borodin, G.D. Smith, Macromolecules 39, 1620 (2006).

[9] N. Petzetakis, C.M. Doherty, A.W. Thornton, X.C. Chen, P. Cotanda, A.J. Hill, N.P. Balsara, $\mathrm{Na}$ ture Commun. 6, 7629-1 (2015).

[10] S.T. Tao, J. Chem. Phys. 56, 5499 (1972).

[11] M. Eldrup, D. Lightbody, J.N. Sherwood, Chem. Phys. 63, 51 (1981).

[12] H. Nakanishi, S.J. Wang, Y.C. Jean, in: Positron Annihilation Studies of Fluids, Ed. S.C. Sharam, World Sci., Singapore 1988, p. 292.

[13] J.V. Olsen, P. Kirkegaard, N.J. Pedersen, M. Eldrup, Phys. Status Solidi C 4, 4004 (2007).
[14] S. Devikal, P. Kamaraja, M. Arthanareeswari, Chem. Sci. Trans. 2, S129 (2013).

[15] K. Hagiwara, T. Ougizawa, T. Inoue, K. Hirata, Y. Kobayashi, J. Rad. Phys. Chem. 58, 525 (2000).

[16] H. Park, Y. Kim, W.H. Hong, Y.S. Choi, H. Lee, Macromolecules 38, 2289 (2005).

[17] Y. Park, Y. Yamazaki, Polym. Bull. 53, 181 (2005).

[18] H.F.M. Mohamed, Y. Ito, M. Imai, J. Chem. Phys. 105, 4841 (1996).

[19] H.F.M. Mohamed, K. Ito, Y. Kobayashi, N. Takimoto, Y. Takeoka, A. Ohira, Polymer 49, 3091 (2008).

[20] C.L. Wang, Y. Kobayashi, W. Zheng, C. Zhang, Y. Nagai, M. Hasegawa, Phys. Rev. B 63, 064204 (2001).

[21] M. Hema, S. Selvasekarapandian, H. Nithya, A. Sakunthala, D. Arunkumar, Ionics 15, 487 (2009).

[22] N. Agmon, Chem. Phys. Lett. 244, 456 (1995).

[23] F. Loureiro, E.S. de Marins, G.D.C. dos Anjos, A.M. Rocco, R.P. Pereira, Polímeros 24, 49 (2014).

[24] R.K. Nagarale, G.S. Gohil, V.K. Shahi, J. Membrane Sci. 280, 389 (2006).

[25] T. Miyamoto, K. Shibayama, J. Appl. Phys. 44 5372 (1973)

[26] S.J. Pas, M.D. Ingram, K. Funke, A.J. Hill, Electrochim. Acta 50, 3955 (2005). 